\title{
Intoxicação natural por Brachiaria spp. em ovinos no Brasil Central $^{1}$
}

\author{
Vanessa S. Mustafa ${ }^{2}$, Augusto Ricardo Coelho Moscardini' ${ }^{3}$, José R.J. Borges ${ }^{4}$, \\ Guilherme Carneiro Reckziegel ${ }^{5}$, Franklin Riet-Correa ${ }^{6}$ e Márcio B. Castro ${ }^{2 *}$
}

\begin{abstract}
Mustafa V.S., Moscardini A.R.C., Borges J.R.J., Reckziegel G.C., Riet-Correa F. \& Castro M.B. 2012. [Brachiaria spp. poisoning in sheep in Central Brazil.] Intoxicação natural por Brachiaria spp. em ovinos no Brasil Central. Pesquisa Veterinária Brasileira 32(12):1272-1280. Laboratório de Patologia Veterinária, Hospital Veterinário, Universidade de Brasília, Campus Universitário Darcy Ribeiro, Via L4 Norte, Cx. Postal 4508, Brasília, DF 70910-970, Brazil. E-mail: mbcastro@unb.br

Brachiaria spp. is the main pasture for ruminants in Central-Brazil, but the crucial problem for their utilization is the toxicity due to the presence of steroidal saponins. This paper reports 35 outbreaks of poisoning by Brachiaria spp in sheep. The poisoning occurred in different seasons of the year. Mean morbidity was $23.2 \%$ and mean lethality was $88.3 \%$. The occurrence of clinical signs after the introduction of the sheep into the pastures varied from 15 days to more than 12 months. In $90.1 \%$ of the outbreaks, sheep younger than 12 months of age were affected. Clinical signs and gross lesions were characteristic of hepatogenous photosensitization, but more acute cases showed edema of the face and ears, without dermatitis or jaundice. The main histologic lesions of the liver were the presence of macrophages with foamy cytoplasm, found mainly in sinusoids, and sometimes containing negative images of crystals. In eight out of 11 farms visited the outbreaks occurred in Brachiaria decumbens pastures, two in B. brizantha pastures, and one in a pasture of $B$. decumbens, B. humidicola, and Andropogon sp. Saponin concentrations in the pastures of 11 outbreaks varied from 0.3 to $2.56 \%$. The information generated by this report allows the proposal of measures for control and prevention of Brachiaria spp. poisoning in Central-Brazil.
\end{abstract}

INDEX TERMS: Poisonous plants, Brachiaria spp., steroidal saponins, plant poisoning, sheep, Central-Brazil.

RESUMO.- Brachiaria spp. é a principal forrageira utilizada para ruminantes no Brasil Central, mas a sua toxicidade, devida à presença de saponinas esteroidais, torna-se um importante entrave à sua utilização. Neste trabalho descrevem-se 34 surtos e um foco de intoxicação por Brachiaria spp em ovinos, que ocorreram em diferentes épocas do ano.

\footnotetext{
${ }^{1}$ Recebido em 17 de fevereiro de 2012.

Aceito para publicação em 28 de setembro de 2012.

${ }^{2}$ Laboratório de Patologia Veterinária, Hospital Veterinário (Hvet), Universidade de Brasília (UnB), Via L4 Norte, Cx. Postal 4508, Brasília, DF 70910-970, Brasil. *Autor para correspondência: mbcastro@unb.br

${ }^{3}$ Centro de Medicina Veterinária, RPMon, DF75 Km 8, Riacho Fundo 1, Brasília, DF 71801-750.

${ }^{4}$ Hospital Veterinário de Grandes Animais UnB, Granja do Torto, Via L4 Norte, Cx. Postal 4508, Brasília, DF.

${ }^{5}$ Médico Veterinário autônomo, SHCES 1205, Bloco D, Apto 101, Cruzeiro Novo, Brasília, DF 70658-254.

${ }^{6}$ Hospital Veterinário, Universidade Federal de Campina Grande, Patos, PB 58700-000, Brasil.
}

A morbidade geral foi de $23,2 \%$ e a letalidade foi $88,3 \%$. 0 tempo que os animais permaneceram no pasto até o surgimento dos sinais clínicos da intoxicação por Brachiaria spp. variou de 15 dias até mais de 12 meses. Em 90,1\% dos surtos os animais eram menores de 12 meses de idade. 0 curso clínico da intoxicação variou de 2 a 45 dias. Os sinais clínicos e as lesões macroscópicas foram características de fotossenssibilização hepatógena, no entanto, nos casos mais agudos não foram observadas dermatite nem icterícia, ocorrendo severo edema em face e orelhas. Na histologia do fígado as lesões mais características foram a presença de macrófagos com citoplasma espumoso, encontrados principalmente nos sinusoides hepáticos e, às vezes, com imagens negativas de cristais acutiformes no citoplasma. Em oito das 11 fazendas visitadas os surtos ocorreram em pastagens de Brachiaria decumbens; em duas em pastagens de $B$. brizantha e uma em pastagem de B. decumbens, $B$. humidicola e Andropogon sp. As concentrações de saponinas 
nas pastagens, em 5 surtos, variou de $0.3 \%$ a $2.56 \%$. As informações geradas neste trabalho permitem a proposta de medidas para controle e profilaxia da intoxicação por Brachiaria spp. no Brasil Central.

TERMOS DE INDEXAÇÃO: Plantas tóxicas, Brachiaria spp., steroidal saponins, intoxicação por plantas, ovinos, Brasil Central.

\section{INTRODUÇÃO}

Brachiaria spp. é a principal forrageira utilizada na formação de pastagens no Brasil Central, sendo uma importante opção de alimentação na ovinocultura. Entretanto, devido à toxicidade dessas gramíneas para os ruminantes, torna-se um importante entrave à ovinocultura nacional (Castro et al. 2007).

O princípio tóxico da braquiária é um componente da própria planta, identificado como sendo uma saponina litogênica, chamada de protodioscina, que causa hepatotoxicidade, obstrução de ductos biliares e fotossensibilização (Graydon et al. 1991, Salam Abdullah et al. 1992, Lemos et al. 1997, Driemeier et al. 1999, Stegelmeier 2002, Wisløff et al. 2002, Brum et al. 2007, Santos Jr 2008).

Os principais sinais clínicos observados nos animais intoxicados pela gramínea são lesões cutâneas eritematosas, com presença de crostas e prurido principalmente em regiões despigmentadas ou desprovidas de pelos (Lemos et al. 1996, Barbosa et al. 2006, Brum et al. 2007, Mendonça et al. 2008, Santos Jr 2008, Santos et al. 2008, Castro et al. 2011). Os animais intoxicados por Brachiaria spp. demonstram com frequência icterícia, hepatomegalia e fígado com coloração amarelada intensa (Lemos et al. 1996, Driemeier et al. 1998, Lemos \& Purisco 2002, Brum et al. 2007, Mendonça et al. 2008). Ovinos acometidos pela intoxicação apresentam no fígado aglomerados de macrófagos com o citoplasma espumoso nos sinusoides, muitos apresentando imagens negativas de cristais aculiformes em seu citoplasma, também presentes no interior de hepatócitos e obstruindo a luz de ductos biliares (Graydon et al. 1991, Driemeier et al. 1999, Gomar et al. 2005, Brum et al. 2007).

Apesar dos diversos estudos desenvolvidos no intuito de descrever a ocorrência e os aspectos clínico-patológicos da intoxicação de ruminantes pela braquiária, ainda existem muitas lacunas no conhecimento dos seus aspectos epidemiológicos. Ainda são desconhecidos os fatores que possam interagir na ocorrência dessa intoxicação, em especial, nos ovinos, consideradas uma das espécies mais suscetíveis. Esse trabalho teve o intuito de investigar a intoxicação natural por Brachiaria spp. em ovinos no Brasil Central, para compreender melhor os fatores epidemiológicos e clínico-patológicos envolvidos no seu surgimento, visando estabelecer medidas no futuro para a utilização segura de pastagens da gramínea, contribuindo para o desenvolvimento da ovinocultura regional.

\section{MATERIAL E MÉTODOS}

0 presente trabalho foi conduzido em duas etapas. Na primeira, foram realizadas visitas e colhidas informações diretamente nas propriedades onde ocorreram casos de intoxicação natural por Brachiaria spp. em ovinos de 2006 a 2008 (grupo S). Foram ava- liados 1 foco e 10 surtos, anotados em formulário padronizado contendo as características das propriedades, informações sobre os animais e rebanhos no momento do diagnóstico. Os índices de morbidade, mortalidade e letalidade foram calculados a partir das informações recolhidas e apresentados juntos a outros estudos no País para comparação.

Na segunda etapa, foi realizado um estudo retrospectivo com as informações levantadas a partir das fichas de atendimentos clínicos e das necropsias de ovinos intoxicados por braquiária, realizados no Hospital Escola de Grandes Animais da Universidade de Brasília (Hvet-UnB) e no Laboratório de Patologia Veterinária da Universidade de Brasília (LPV-UnB) nos anos de 2002 a 2008 (grupo L), onde foram avaliados 24 surtos.

As informações obtidas foram utilizadas para determinar época do ano de ocorrência dos surtos, as espécies de Brachiaria envolvidas na intoxicação, os principais sinais clínicos e sua prevalência, o tempo de introdução dos animais nos pastos e a idade dos animais acometidos. Nas propriedades visitadas foram observados a altura da pastagem e o estágio vegetativo da forrageira, sendo classificado em estágios de brotação, sementação ou após queda das sementes.

Foi levantado o índice pluviométrico dos meses e anos correspondentes junto ao Instituto Nacional de Meteorologia (INMET) para os locais dos surtos. 0 índice pluviométrico médio (IPVM) é a média aritmética desses valores para cada mês.

Nas propriedades visitadas foram colhidas amostras de $\mathrm{Bra}$ chiaria sp. a aproximadamente $2 \mathrm{~cm}$ da superfície o solo, em no mínimo 10 locais distintos aleatórios do piquete onde os animais se encontravam durante a intoxicação, para contagem de esporos de Pithomyces chartarum e mensuração dos níveis de saponina. A pesquisa de esporos de $P$. chartarum nas pastagens foi realizada no mesmo dia da coleta, em amostras frescas (Di Menna \& Bailey 1973).

0 restante da amostra de forrageira colhida foi seca à sombra e em temperatura ambiente para dosagem do teor de protodioscina e metil-protodioscina pelo método de cromatografia líquida sob alta pressão (HPLC) utilizando o detector de evaporação por dispersão de luz (ELSD-Evaporative Light Scattering Detector) utilizando fase reversa (RP-18) em coluna de gradiente de água/ acetonitrila (Gjulemetowa et al. 1982, Barbosa-Ferreira et al. 2009).

Nas propriedades visitadas, quando possível, foi realizada biópsia hepática guiada por ultrassom (Amorim et al. 2003) para exame histopatológico. Os ovinos que morreram durante os surtos foram necropsiados. As amostras foram fixadas em formol a 10\% tamponado. Após fixação, os materiais provenientes das necropsias e biópsias hepáticas foram processados rotineiramente, incluídos em parafina, cortados na espessura média de $5 \mu \mathrm{m}$, corados com hematoxilina e eosina (HE) e analisados em microscopia de luz. As lâminas histológicas de fígado foram reavaliadas por dois patologistas e suas alterações histológicas foram classificadas.

O diagnóstico da intoxicação por Brachiaria spp. foi baseado em histórico e sinais clínicos, achados histopatológicos de biópsias de fígado e necropsias dos animais durante as investigações dos casos.

\section{RESULTADOS}

Nesse estudo foram avaliados 34 surtos e um foco, sendo que 24 desses foram resultantes dos levantamentos nos arquivos do Hvet-UnB e LPV-UnB (L1 a L24) e 10 surtos e um foco (S5) foram acompanhados nas propriedades pela equipe do LPV-UnB (S1 a S11). Desses, 60\% ocorreram no Distrito Federal, 26,7\% em Goiás e 13,3\% em Minas Gerais. 
Os casos de intoxicação natural por braquiária ocorreram nos meses de março $(5,7 \%)$, abril e maio $(8,6 \%$ em cada mês), junho e julho (11,4\% em cada mês), agosto $(14,3 \%)$, setembro $(11,4 \%)$, outubro $(14,3 \%)$, novembro $(5,7 \%)$ e dezembro $(8,6 \%)$. Nesses meses o índice pluviométrico variou de $0 \mathrm{~mm}^{3}$ a $400 \mathrm{~mm}^{3}$ (Fig.1).

A morbidade, a mortalidade e a letalidade da intoxicação por braquiária no Brasil Central e de outros surtos e experimentos em ovinos no Brasil estão representados no Quadro 1.

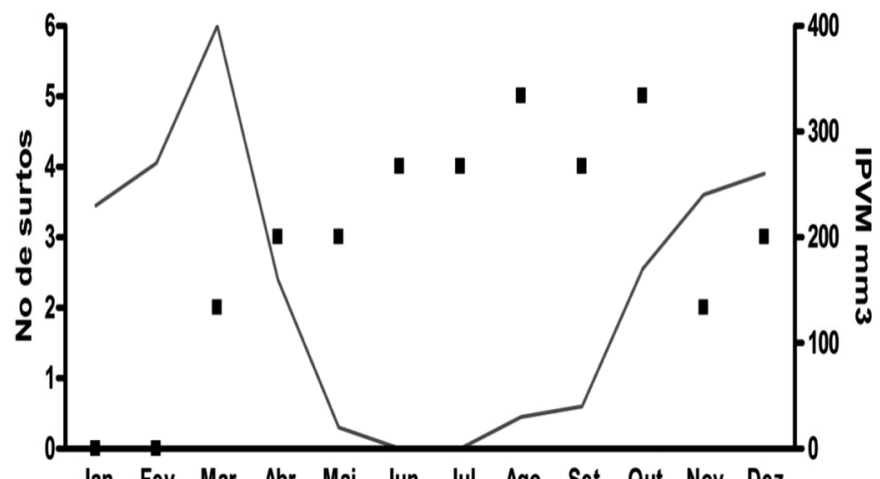

Fig.1. Distribuição dos surtos de intoxicação natural por braquiária em ovinos quanto ao mês de ocorrência (•) e índice pluviométrico médio (-) (IPVM) registrado nesses meses.

Quadro 1. Morbidade, mortalidade e letalidade da intoxicação por Brachiaria spp. em ovinos no Brasil

\begin{tabular}{|c|c|c|c|c|c|c|}
\hline Ref. & Local & Tipo & $\begin{array}{c}\text { № de } \\
\text { animais }\end{array}$ & $\begin{array}{c}\text { Morbi- } \\
\text { dade }(\%)^{*}\end{array}$ & $\begin{array}{l}\text { Mortali- } \\
\text { dade }(\%)^{*}\end{array}$ & $\begin{array}{c}\text { Letali- } \\
\text { dade }(\%)^{*}\end{array}$ \\
\hline $\begin{array}{l}\text { Brasil Central } \\
(2009)^{* *}\end{array}$ & $\begin{array}{l}\text { DF, GO } \\
\text { e MG }\end{array}$ & $\mathrm{N}$ & $\mathrm{n}=1305$ & 23,2 & 20 & 86,5 \\
\hline $\begin{array}{l}\text { Mendonça et al. } \\
\text { (2008) }\end{array}$ & MT & $\mathrm{N}$ & $\mathrm{n}=40$ & 37,5 & 17,5 & 46,7 \\
\hline Santos Jr (2008) & DF & $\mathrm{E}$ & $\mathrm{n}=21$ & 57,1 & 42,8 & 75 \\
\hline Brum et al. (2007) & MS & $\mathrm{N}$ & $n=28$ & 25 & 21,4 & 85,7 \\
\hline Castro et al. (2007) & DF & $\mathrm{E}$ & $n=20$ & 50 & 15 & 30 \\
\hline Silva et al. (2006) & $\mathrm{RN}$ & $\mathrm{N}$ & $n=200$ & 25 & 25 & 100 \\
\hline Soares et al. (2000) & PE & $\mathrm{N}$ & $\mathrm{n}=110$ & 15,4 & 4,5 & 29,4 \\
\hline Lemos et al. (1996) & MS & $\mathrm{N}$ & $n=163$ & 31,3 & 18,4 & 58,8 \\
\hline
\end{tabular}

$\overline{\mathrm{N}}=$ intoxicação natural, $\mathrm{E}=$ intoxicação experimental. * Valores calculados com base nos dados publicados, ** Valores médios das informações de surtos acompanhados no DF, GO e MG.

Em $90,1 \%$ dos casos acompanhados os animais intoxicados tinham menos de um ano de idade. 0 tempo de permanência dos animais no pasto, antes de aparecerem os sinais de intoxicação, variou de 15 dias a mais de 12 meses. No único foco avaliado nesse estudo (S5), o animal nasceu e permaneceu no mesmo pasto até a fase adulta, quando apresentou o quadro de fotossensibilização. 0 curso clínico da intoxicação variou de dois dias a 45 dias (Quadro 2). Em três propriedades visitadas (S1, S5 e S11) não foi possível determinar o período entre o aparecimento dos primeiros sinais clínicos e a resolução da doença.

Em 54,5\% das propriedades acompanhadas, a intoxicação natural por braquiária ocorreu em animais nascidos na propriedade, e em $45,5 \%$, os animais intoxicados haviam sido recém-adquiridos de outras localidades, principalmente da Região Nordeste.
Quadro 2. Idade dos animais afetados, tempo de permanência no pasto e curso clínico da intoxicação por Brachiaria spp. em ovinos no Brasil Central

\begin{tabular}{cccc}
\hline Propriedades & Idade dos animais & Tempo no pasto & Curso clínico \\
\hline S 1 & $0-6$ meses & 30 dias & - \\
S 2 & $6-12$ meses & 60 dias & 30 dias \\
S 3 & $6-12$ meses & 120 dias & 4 dias \\
S 4 & $0-6$ meses & 45 dias & 2 dias \\
S 5 & Adulta & $*$ & - \\
S 6 & $0-6$ meses & 60 dias & 45 dias \\
S 7 & $6-12$ meses & 15 dias & 40 dias \\
S 8 & $6-12$ meses & 52 dias & 4 dias \\
S 9 & $0-12$ meses & 45 dias & 45 dias \\
S 10 & $6-12$ meses & 30 dias & 15 dias \\
S 11 & $0-6$ meses & 30 dias & -
\end{tabular}

* O animal nascido e mantido sempre no mesmo pasto. - Informação não registrada.

Quadro 3. Principais sinais clínicos encontrados em ovinos naturalmente intoxicados por Brachiaria spp. no Brasil Central

\begin{tabular}{llll}
\hline Propriedade & \multicolumn{4}{c}{ Sinais clínicos } \\
\cline { 2 - 4 } & EDF DER HDO EPÍ CEG DN ICT DIS PEF LUP AAE
\end{tabular}

\begin{tabular}{|c|c|c|c|c|c|c|c|c|c|c|c|}
\hline L 1 & + & - & - & - & - & + & - & - & + & - & + \\
\hline L 2 & + & - & + & - & - & - & - & - & - & + & - \\
\hline L 3 & + & + & - & - & - & - & - & - & - & - & - \\
\hline L 4 & - & - & - & - & - & - & + & - & + & - & + \\
\hline L 5 & - & + & - & - & - & + & + & - & - & - & - \\
\hline L 6 & + & + & + & - & - & - & - & - & + & - & - \\
\hline L 7 & + & - & + & - & - & - & - & - & - & - & - \\
\hline L 9 & - & - & + & - & - & - & - & - & + & - & - \\
\hline L 10 & - & + & + & - & - & - & - & - & - & - & - \\
\hline L 11 & + & - & - & - & - & - & - & - & - & - & - \\
\hline L 12 & - & + & + & - & - & + & - & - & - & - & - \\
\hline L 13 & - & - & - & - & - & - & - & + & - & - & - \\
\hline L 15 & - & - & + & - & - & + & - & - & - & - & - \\
\hline L 16 & - & - & - & - & - & - & - & + & - & - & + \\
\hline L 18 & - & - & - & - & - & - & - & - & - & - & + \\
\hline L 19 & - & + & + & + & - & - & - & - & - & - & - \\
\hline L 21 & + & - & + & + & - & - & - & - & + & - & - \\
\hline L 22 & + & + & + & - & - & - & - & - & - & - & - \\
\hline L 24 & - & + & - & - & - & - & - & - & - & - & + \\
\hline S 1 & - & + & - & - & - & - & - & - & - & - & - \\
\hline S 2 & - & + & + & - & - & - & + & - & - & - & + \\
\hline S 3 & + & - & - & - & - & - & - & - & - & - & + \\
\hline S 4 & + & - & + & - & + & + & - & - & - & - & - \\
\hline S 5 & - & + & + & - & - & - & - & - & - & - & - \\
\hline S 6 & - & + & + & - & - & + & - & - & - & - & - \\
\hline S 7 & + & - & - & - & - & - & - & - & + & - & + \\
\hline S 8 & + & - & - & - & - & + & + & - & + & - & + \\
\hline S 9 & + & - & - & - & - & - & - & - & - & - & + \\
\hline S 10 & + & - & - & - & - & - & - & - & + & - & + \\
\hline S 11 & + & + & - & - & + & - & - & - & - & - & + \\
\hline
\end{tabular}

$\overline{\mathrm{EDF}}=$ edema de face, $\mathrm{DER}=$ dermatite em face e orelhas, $\mathrm{HDO}=$ hiperemia e/ou descarga ocular, EPI = epífora, $\mathrm{CEG}=$ cegueira, $\mathrm{DN}=$ descarga nasal, ICT = icterícia, DIS = dispneia, $\mathrm{PEF}=$ pelos eriçados e/ou foscos, LUP = lesões ulcerativas na pele do úbere, AAE = apatia, anorexia e emagrecimento. - Ausente, + presente.

Os principais sinais clínicos (Quadro 3) observados nos casos de intoxicação natural por braquiária no Brasil Central foram edema de face $(42,8 \%)$, seguido de hiperemia e descarga ocular mucoide (40\%), dermatite em face e/ou orelhas (Fig.2) em 37,1\% dos animais, apatia, anorexia e emagrecimento $(34,3 \%)$ e descarga nasal $(20 \%)$. Icterícia foi observada em $12,1 \%$ dos casos de intoxicação natural 


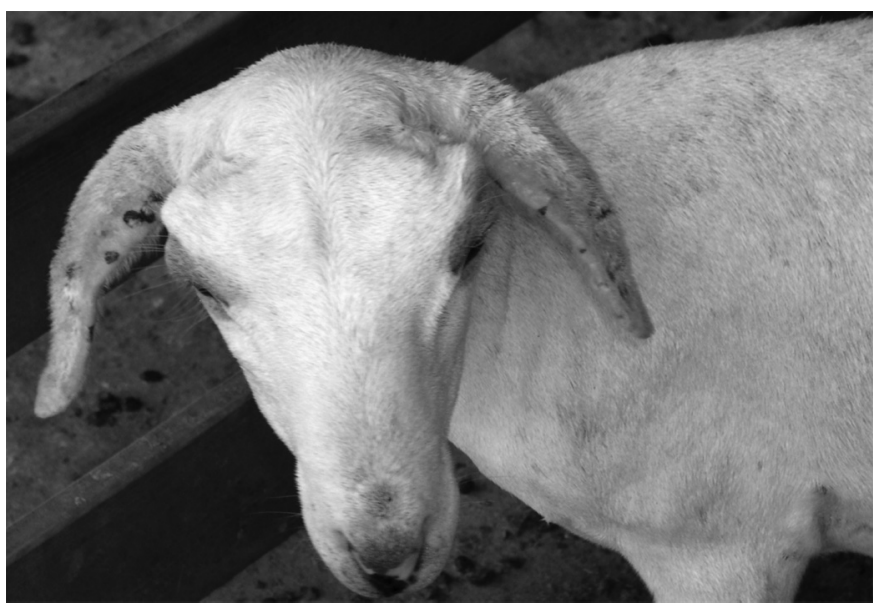

Fig.2. Ovino naturalmente intoxicado por Brachiaria spp. demonstrando fotossensibilização caracterizada por hiperemia da pele e edema de orelhas.

Quadro 4. Principais achados de necropsia dos ovinos intoxicados por Brachiaria spp. no Brasil Central

\begin{tabular}{ccccccccccccc}
\hline PR & AN & \multicolumn{10}{c}{ Achados de necropsia } \\
\cline { 2 - 11 } & & ACH & HPM & PLE & VBR & EMA & SCA & AGA & ASC & HIT & HIP \\
\hline L16 & a & + & - & - & - & - & - & - & - & - & - \\
L17 & a & + & - & - & - & - & - & - & - & - & - \\
L18 & a & + & - & + & - & + & - & + & + & + & - \\
L22 & a & + & + & - & - & - & + & - & - & - & - \\
L23 & a & + & - & - & - & - & - & - & - & - & - \\
L24 & a & + & - & - & - & + & - & + & - & - & + \\
S3 & a & - & + & - & - & - & + & - & + & - & - \\
& b & - & + & - & - & - & + & - & - & - & - \\
& c & + & + & - & - & - & - & - & - & - & - \\
S4 & a & - & - & + & - & + & - & + & + & - & - \\
S7 & a & + & + & - & - & - & + & - & - & - & - \\
& b & + & - & - & - & - & - & - & - & - & - \\
S8 & a & + & + & - & - & + & + & - & - & - & - \\
S9 & a & + & + & - & + & - & - & + & - & - & - \\
S10 & a & + & + & + & - & + & - & - & - & - & - \\
S11 & a & - & - & - & - & + & + & + & - & - & -
\end{tabular}

PR = Propriedade, $\mathrm{AN}=$ Animal, $\mathrm{ACH}=$ Alteração na coloração hepática, HPM = Hepatomegalia, PLE = Padrão lobular evidente, $\mathrm{VBR}=$ Vesícula biliar repleta, $\mathrm{EMA}=$ Emaciação, $\mathrm{SCA}=$ Tecido subcutâneo amarelado, AGA = Atrofia gelatinosa do tecido adiposo, ASC = Ascite, $\mathrm{HIT}=$ Hidrotórax, HIP = Hidropericárdio.

- Ausente, + presente. As letras a, b, c representam animais diferentes em uma mesma propriedade.

pela gramínea. Não foram observados sinais clínicos em três animais de propriedades diferentes (L8, L10 e L23) que manifestaram a forma aguda da intoxicação.

Os achados de necropsia encontrados com maior frequência nos ovinos intoxicados (Quadro 4) foram alteração na coloração do fígado (75\%) (Fig.3), hepatomegalia (50\%), emaciação $(37,5 \%)$, tecido subcutâneo ictérico $(37,5 \%)$, atrofia gelatinosa do tecido adiposo $(31,25 \%)$, evidenciação do padrão lobular do fígado (18,75\%) e ascite $(18,75 \%)$. Vesícula biliar distendida e repleta foi observada em $6,25 \%$ dos animais necropsiados.

As principais alterações histopatológicas observadas (Quadro 5) foram tumefação e vacuolização de hepatócitos (Fig.4A) em 90,0\% dos casos, macrófagos com citoplasma de aspecto espumoso no interior dos sinusoides hepáticos
(Fig.4B) em 63,6\% das amostras, hiperplasia de ductos biliares (81,8\%), fibroplasia periportal (Fig.5A) em 68,2\% e infiltrado inflamatório mononuclear periportal em $72,7 \%$ (Fig.5B). Imagens negativas de material cristaloide acicular no citoplasma de macrófagos espumosos e necrose individual de hepatócitos (Fig.5B) foram observadas também em alguns animais.

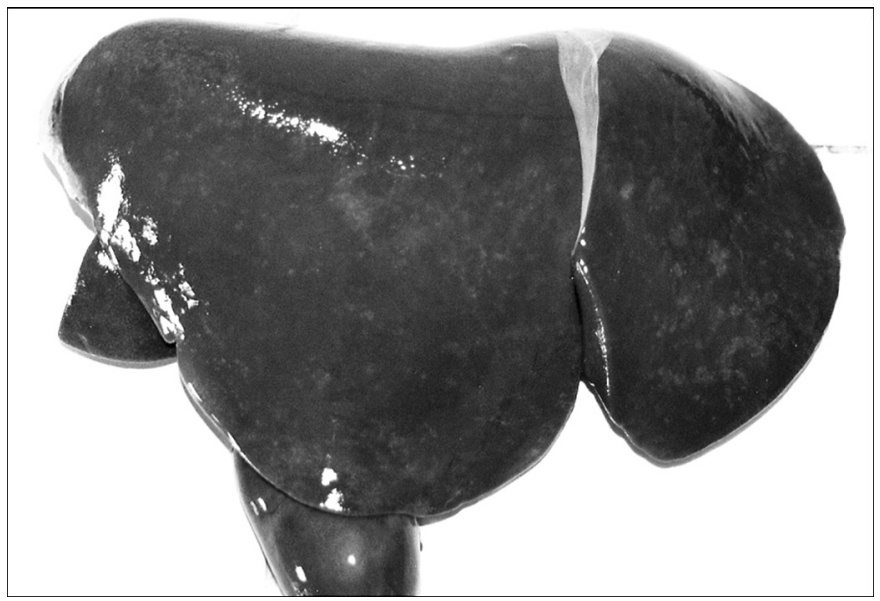

Fig.3. Fígado de ovino naturalmente intoxicado por Brachiaria spp. apresentando coloração acastanhada, com áreas multifocais esbranquiçadas. A vesícula biliar está repleta e distendida.

Quadro 5. Principais achados histopatológicos encontrados nos fígados de ovinos intoxicados por Brachiaria spp.

\begin{tabular}{|c|c|c|c|c|c|c|c|c|c|c|c|c|}
\hline \multirow[t]{2}{*}{ PR } & \multirow[t]{2}{*}{ AN } & \multicolumn{11}{|c|}{ Alterações histopatológicas } \\
\hline & & $\mathrm{B} / \mathrm{N}$ & TVH & ME & $\mathrm{CCM}$ & $\mathrm{NIH}$ & HDB & $\mathrm{COL}$ & FBP & IMP & CG & INF \\
\hline L8 & & $\mathrm{N}$ & ++ & ++ & - & ++ & ++ & - & + & - & - & - \\
\hline L14 & & $\mathrm{N}$ & ++ & + & + & + & ++ & - & ++ & + & - & + \\
\hline L16 & & $\mathrm{N}$ & ++ & - & - & + & - & + & - & +++ & - & - \\
\hline L17 & & $\mathrm{N}$ & ++ & - & - & ++ & + & + & +++ & ++ & - & - \\
\hline L22 & & $\mathrm{N}$ & +++ & ++ & - & ++ & + & - & ++ & ++ & - & - \\
\hline L24 & & $\mathrm{N}$ & + & ++ & - & + & ++ & + & + & - & - & - \\
\hline \multirow[t]{5}{*}{ S3 } & a & B & ++ & + & + & + & + & - & - & + & + & - \\
\hline & $b$ & B & ++ & + & - & - & - & - & + & + & - & - \\
\hline & c & $\mathrm{N}$ & ++ & + & - & + & + & - & + & + & - & - \\
\hline & $\mathrm{d}$ & $\mathrm{N}$ & ++ & ++ & + & + & + & + & - & + & - & - \\
\hline & e & $\mathrm{N}$ & ++ & ++ & + & + & + & - & + & - & ++ & - \\
\hline S4 & & $\mathrm{N}$ & - & +++ & ++ & ++ & ++ & - & - & - & - & - \\
\hline S5 & & B & - & - & - & + & ++ & - & - & + & - & - \\
\hline \multirow[t]{2}{*}{ S6 } & $\mathrm{a}$ & B & ++ & + & - & ++ & + & - & - & + & - & - \\
\hline & $\mathrm{b}$ & B & + & - & - & - & - & - & - & + & - & - \\
\hline \multirow[t]{2}{*}{ S7 } & $\mathrm{a}$ & $\mathrm{N}$ & ++ & ++ & - & - & ++ & ++ & ++ & - & - & - \\
\hline & b & $\mathrm{N}$ & + & - & - & + & + & + & + & + & - & - \\
\hline \multirow[t]{2}{*}{ S8 } & $\mathrm{a}$ & B & + & - & - & - & - & - & + & - & - & + \\
\hline & b & $\mathrm{N}$ & ++ & - & - & - & + & + & + & + & - & - \\
\hline S9 & & $\mathrm{N}$ & + & ++ & - & + & + & - & + & + & - & - \\
\hline $\mathrm{S} 10$ & & $\mathrm{~N}$ & +++ & - & - & - & ++ & ++ & + & - & - & + \\
\hline S11 & & $\mathrm{N}$ & +++ & ++ & - & - & + & + & + & ++ & - & - \\
\hline
\end{tabular}

$\mathrm{PR}=$ Propriedade, $\mathrm{AN}=$ Animal, $\mathrm{B} / \mathrm{N}=$ Procedência do material, $\mathrm{B}=\mathrm{Bi}-$ ópsia, $\mathrm{N}=$ Necropsia, TVH = Tumefação e vacuolização de hepatócitos, $\mathrm{ME}=$ Macrófago com citoplasma espumoso, $\mathrm{CCH}=$ Imagem negativa de cristais no citoplasma de macrófago, $\mathrm{NIH}=$ Necrose individual de hepatócitos, $\mathrm{HDB}=$ Hiperplasia de ductos biliares, $\mathrm{COL}=$ Colestase, $\mathrm{FBP}$ $=$ Fibroplasia periportal, $\mathrm{IMP}=$ Infiltrado mononuclear periportal, $\mathrm{CG}=$ Células gigantes, INF = Infiltrado neutrofílico focal.

Avaliação histopatológica: - ausência. + discreta. ++ moderada. +++ acentuada.

As letras a, b, c, d, e representam animais diferentes em uma mesma propriedade. 


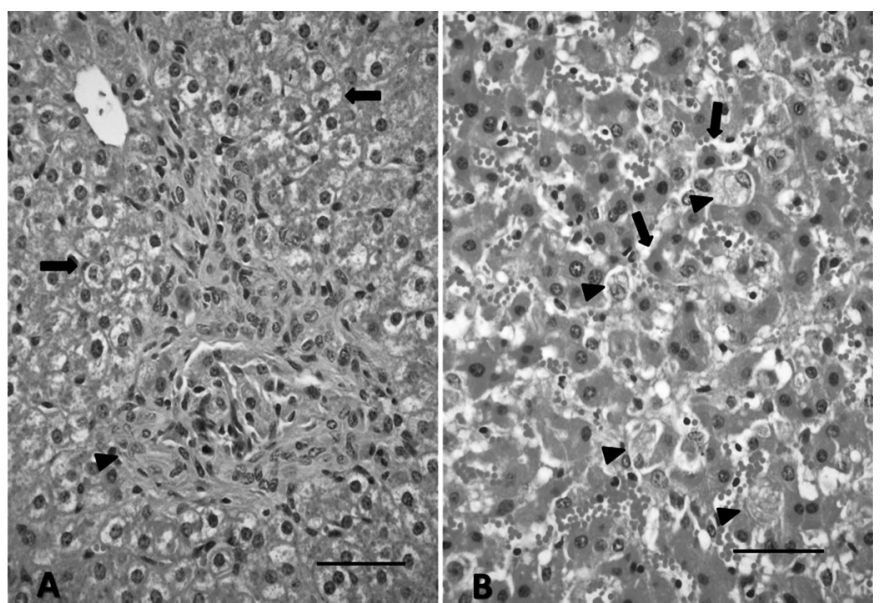

Fig.4. Fígados de ovinos naturalmente intoxicados por Brachiaria spp. (A) Observam-se vacuolização de hepatócitos (seta), hiperplasia moderada de ductos biliares e fibroplasia periportal discreta (cabeça de seta). (B) Observam-se macrófagos espumosos com imagem de cristais intracitoplasmáticos (cabeça de seta) e necrose individual de hepatócitos (seta). HE, obj.40x. (Barra=50 $\mu \mathrm{m})$

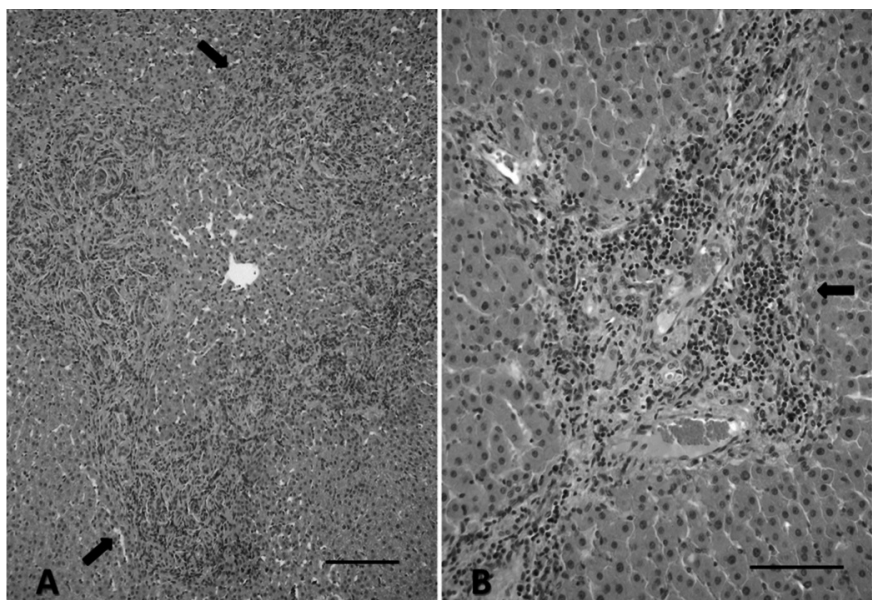

Fig. 5. Fígado de ovino naturalmente intoxicado por Brachiaria spp. A: Observa-se hiperplasia acentuada de ductos biliares com fibroplasia periportal moderada (seta). Coloração HE.

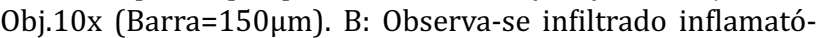
rio mononuclear moderado na região periportal (seta). HE, obj.20x (Barra=100 $\mu \mathrm{m})$.

As espécies de braquiária mais prevalentes nas propriedades acompanhadas (S1 a S11), a altura das pastagens e seu estágio de desenvolvimentos são apresentados no Quadro 6. 0 nível de saponina nas pastagens em cinco das propriedades acompanhadas variou de 0,30 a $2,56 \%$ na matéria seca. Não foram observados esporos de Pithomyces chartarum em $81,8 \%$ dos pastos avaliados. Em 9,1\% das amostras foram encontrados 5 mil esporos por grama de folhas frescas, e em uma propriedade $(9,1 \%)$, foram observados 25 mil esporos de $P$. chartarum por grama de folhas frescas.

\section{DISCUSSÃO}

Existem poucos estudos epidemiológicos a respeito da intoxicação natural de ruminantes por braquiária no Brasil,
Quadro 6. Tipo de forrageira, altura do pasto e estágio vegetativo nos surtos de intoxicação natural de ovinos por braquiária no Brasil Central

\begin{tabular}{clcl}
\hline Surtos & \multicolumn{1}{c}{ Tipo de braquiária } & $\begin{array}{c}\text { Altura do } \\
\text { pasto }(\mathrm{cm})\end{array}$ & Estágio vegetativo \\
\hline S 1 & B. decumbens & 40 & Sementação \\
S 2 & B. decumbens & 60 & Após queda das sementes \\
S 3 & B. decumbens & 50 & Sementação \\
S 4 & B. decumbens & 50 & Após queda das sementes \\
S 5 & B. decumbens & $15-20$ & Brotação \\
S 6 & B. decumbens & $*$ & Brotação \\
S 7 & B. brizantha & $50-60$ & Sementação \\
S 8 & B. decumbens & $>60$ & Após queda das sementes \\
S 9 & B. decumbens, B. humidi- & 20 & Brotação \\
& cola e Androprogon spp. & & \\
S 10 & B. brizantha & 25 & Brotação \\
S 11 & B. decumbens & $5-20$ & Brotação \\
\hline
\end{tabular}

* Informação não registrada.

em especial, para a espécie ovina. Até o momento não é possível calcular o impacto que a utilização da gramínea tem na ovinocultura nacional. No entanto, devido a sua grande difusão no País, suas qualidades como forrageira e seu baixo custo de implantação e manutenção, é uma importante opção na alimentação de ovinos, especialmente na região Centro-Oeste.

No Brasil Central foram observados casos de intoxicação natural por Brachiaria spp. em ovinos praticamente durante todo o ano. Não houve diferença significativa entre a ocorrência de casos no período seco ou chuvoso.

Em Mato Grosso do Sul foram relatados surtos de intoxicação natural por Brachiaria spp. nos meses de julho, agosto e outubro em ovinos, e nos meses de maio e junho em caprinos (Lemos et al. 1996, 1998). Surtos de intoxicação por Brachiaria spp. podem ocorrer durante todo o ano em ovinos e bovinos em Mato Grosso do Sul, porém a maior incidência desses surtos acontece no início do período chuvoso (Lemos et al. 2011). Nos estados de Mato Grosso (Mendonça et al. 2008), São Paulo (Purchio et al. 1998), Rio Grande do Norte (Silva et al. 2006) e Rio Grande do Sul (Rissi et al. 2007, Schild 2007,) são descritos surtos de intoxicação pela gramínea em ovinos e bovinos tanto no início do período de maior incidência de chuvas quanto no período de seca.

A intoxicação por braquiária em ruminantes é descrita ao longo de todos os meses do ano no Brasil (Riet-Correa $\&$ Mendez 2007). Os surtos avaliados em ovinos no Brasil Central confirmaram estas observações. Ainda existem poucos subsídios que permitam afirmar as razões envolvidas no surgimento dos surtos de intoxicação pela gramínea durante todas as estações do ano. Porém, é importante ressaltar que os ovinos são considerados, dentre os ruminantes, uma das espécies mais suscetíveis à essa intoxicação (Khairi et al. 2000). Esse fato poderia contribuir para a ocorrência dos surtos durante quase todos os meses do ano, mesmo em períodos em que a forrageira apresenta menor quantidade do princípio tóxico.

A morbidade na intoxicação natural por Brachiaria spp. em ovinos no Brasil Central $(23,2 \%)$ é semelhante à observada em ovinos intoxicados pelo capim no Rio Grande do 
Norte e em Mato Grosso do Sul (25\%) (Silva et al. 2006, Brum et al. 2007), porém menor do que a encontrada anteriormente em Mato Grosso do Sul (31,3\%) (Lemos et al. 1996) e em Mato Grosso (37,5\%) (Mendonça et al. 2008). No estado de Pernambuco, 15,4\% dos ovinos adoeceram em um surto de intoxicação natural por braquiária (Soares et al. 2000). Em condições experimentais, a taxa de morbidade da intoxicação de ovinos pela gramínea variou entre 42,8\% e 50\% (Castro et al. 2007, Santos Jr. 2008).

Nos surtos acompanhados foi constatada mortalidade de $20 \%$, valor este semelhante aos encontrados por Lemos et al. (1996), Brum et al. (2007) e Mendonça et al. (2008) em ovinos intoxicados por braquiária (18,4 a 21,4\%). Esse índice foi maior que o observado por Soares et al. (2000) em Pernambuco (4,5\%), porém menor que o índice de mortalidade observado por Silva et al. (2006) no Rio Grande do Norte (25\%). Segundo Tokarnia et al. (2000) a mortalidade pode variar entre 5 e $50 \%$ em rebanhos de ovinos naturalmente intoxicados por Brachiaria spp. Castro et al. (2007) e Santos Jr (2008) reproduziram experimentalmente a intoxicação pela gramínea em ovinos, com mortalidade de 15 e 42,8\%, respectivamente.

Durante os surtos foi registrada taxa de letalidade de $88,3 \%$. Brum et al. (2007) observaram letalidade semelhante $(85,7 \%)$ em surto de intoxicação natural em ovinos em Mato Grosso do Sul. Esse valor é maior que o observado por Lemos et al. (1996) e Mendonça et al. (2008), que descreveram letalidade de 58,8 e 46,7\%, respectivamente, em surtos naturais de intoxicação por braquiária em ovinos. Soares et al. (2000) e Silva et al. (2006), em condições semelhantes, observaram letalidade de 29,4 a $100 \%$, respectivamente. Ovinos intoxicados experimentalmente em pastagens de $B$. decumbens apresentaram letalidade variando de 30\% (Castro et al. 2007) a 75\% (Santos Jr 2008).

Os resultados nesse estudo sobre morbidade, mortalidade e letalidade apresentam semelhanças, outras vezes diferenças, daqueles descritos nas várias regiões do Brasil. Certamente há características geográficas, climáticas, das pastagens e do rebanho semelhantes em determinadas situações, porém, em muitas delas, completamente divergentes. Há variações enormes quanto às localizações dos surtos, época do ano, ocorrência natural ou experimental, características das pastagens, idade e raças dos animais entre outras. Devido à diversidade de situações, é praticamente impossível inferir com segurança sobre as variáveis que influenciaram nos resultados. Entretanto, é importante ressaltar que o desconhecimento da intoxicação por Brachiaria spp. pelos proprietários pode ter levado a uma retirada tardia dos animais do pasto, elevando assim o índice de letalidade (Tokarnia et al. 2000, Riet-Correa \& Mendez 2007).

De qualquer forma, os resultados observados e comparados aos surtos descritos no Brasil, demonstram que a intoxicação por braquiária em ovinos, na maioria das vezes, é caracterizada por elevada mortalidade, morbidade e letalidade, expondo de forma inequívoca, os prejuízos que a gramínea pode provocar nos plantéis de todo país.

0 tempo que os animais permaneceram no pasto até o surgimento dos sinais clínicos da intoxicação por Brachia- ria spp. foi extremamente variável (15 dias a mais de 12 meses). Santos Jr (2008) demonstrou experimentalmente a intoxicação de ovinos jovens pela forrageira entre 7 e 60 dias após serem introduzidos nas pastagens. Cruz et al. (2001), também de forma experimental, demonstraram a intoxicação de um animal, entre nove ovinos, 89 dias após a introdução do grupo em piquete de Brachiaria decumbens.

A grande variação observada no tempo para o surgimento da intoxicação por Brachiaria spp. em ovinos nos surtos naturais avaliados no País pode ser atribuída a diversos fatores, como idade, variações na toxicidade da gramínea, diferenças na suscetibilidade dos animais. Castro et al. (2011) observaram experimentalmente em ovinos que nunca haviam apresentado contato com braquiária, maior gravidade e suscetibilidade à intoxicação, quando comparados com animais procedentes de plantéis mantidos há vários anos em pastagens dessa gramínea e adaptados ao seu pastejo. As causas responsáveis pelas diferenças de suscetibilidade entre rebanhos de ovinos à intoxicação pela planta ainda são desconhecidos, mas possivelmente existam mecanismos de adaptação ou de seleção natural dos animais mais resistentes ao longo dos anos (Riet-Correa et al. 2009, Castro et al. 2011).

Em 90,1\% dos surtos avaliados os animais eram jovens (menos de 12 meses de idade). Em outros locais do Brasil, surtos de intoxicação por Brachiaria spp. também são mais frequentes em ruminantes jovens (Lemos et al. 1997, Santos et al. 2008, Castro et al. 2011, Lemos et al. 2011). Até o momento, os mecanismos envolvidos nesta maior suscetibilidade de animais jovens são desconhecidos, porém, o fato de ocorrerem menos casos de intoxicação em ovinos adultos, sugere a existência de alguma forma de adaptação ou resistência adquirida dos animais à toxicidade das pastagens.

O curso clínico da intoxicação por braquiária observado nesse estudo foi bastante variável (2-45 dias). Lemos et al. (1996) observaram em Mato Grosso do Sul curso clínico da intoxicação por braquiária em ovinos de três a sete dias. Macêdo et al. (2008) descreveram curso clínico de 30 dias em ovinos e caprinos naturalmente intoxicados em Pernambuco. Schild (2007) descreveu o curso clínico da enfermidade de até 14 dias em bovinos do Rio Grande do Sul intoxicados pela gramínea. Santos Jr (2008) observou a existência de formas clínicas distintas da intoxicação por braquiária, variando o curso clínico de 2 a mais de 30 dias, para as formas hiperagudas e crônica respectivamente. Os achados desse e de outros experimentos demonstram que o curso clínico pode ser bastante curto nos casos mais graves, e longo nas formas brandas ou crônicas da intoxicação.

Os principais sinais clínicos encontrados nos ovinos intoxicados por braquiária no Brasil-Central são semelhantes aos descritos anteriormente em ruminantes no Brasil (Lemos et al. 1996, Brum et al. 2007, Mendonça et al. 2008, Santos Jr 2008, Santos et al. 2008, Riet-Correa et al. 2009, Castro et al. 2011). A dermatite em face e orelhas, com presença de crostas, apesar de estar presente em 36,7\% dos animais intoxicados, a maioria deles não apresentou sinais cutâneos de fotossensibilização. Mendonça et al. (2008) no estado do Mato Grosso, diferentemente, observaram como 
principal sinal clínico, a fotodermatite em ovinos intoxicados pela gramínea, inclusive em áreas de pele pigmentadas.

Santos Jr (2008) demonstrou experimentalmente a ausência de fotossensibilização hepatógena em ovinos intoxicados por braquiária, em sua maioria da raça Santa Inês de pelagem escura, e principalmente, nos casos com evolução mais aguda. Nesse experimento $40 \%$ dos ovinos, mesmo sem lesões cutâneas, apresentaram hiperemia e descarga mucóide na mucosa ocular. Apesar da fotossensibilização ser considerada um dos sinais clínicos mais frequentes na intoxicação por braquiária, possivelmente a sua ausência possa ser explicada pela pele escura dos ovinos estudados e pela evolução muito aguda da intoxicação. 0 mecanismo envolvidos nas alterações da mucosa ocular, até o momento, não foi elucidado, entretanto é possível que ocorram devido a maior sensibilidade da mucosa após acúmulo de pigmentos fotodinâmicos (Tokarnia et al. 2000, Lemos \& Purisco 2002, Santos Jr 2008).

0 edema de face foi o sinal clínico com maior frequência nos ovinos intoxicados $(43,3 \%)$. Essa alteração é frequentemente descrita em ovinos intoxicados por braquiária (Tokarnia et al. 2000, Lemos \& Purisco 2002), porém não existem informações precisas quanto à frequência destes sinais clínicos em casos naturais da doença. 0 edema de face e orelha e o eczema facial são descritos como alterações características e exclusivas de ovinos intoxicados por braquiária (Salam Abdullah et al. 1992). A patogenia dessa alteração ainda não está bem esclarecida. Acredita-se que o principal mecanismo de desenvolvimento dessa alteração esteja correlacionado com o aumento na sensibilidade cutânea decorrente ao acúmulo de filoeritrina (Tokarnia et al. 2000).

A icterícia, em diferentes graus, é descrita com frequência como sinal clínico da intoxicação por Brachiaria spp. em ruminantes (Salam Abdullah et al. 1988, Graydon et al. 1991, Lemos et al. 1998, Lemos \& Purisco 2002, Riet-Correa \& Mendez 2007, Rissi et al. 2007), porém foi visualizada em somente $13,3 \%$ dos animais avaliados nesse estudo. Acredita-se que a causa da icterícia seja a obstrução de vias biliares pelos cristais formados pela conjugação das saponinas presente nas espécies de braquiária (Cruz et al. 2000, 2001). Essa obstrução provoca colestase, diminuição da excreção de pigmentos biliares e outros metabólitos promovendo o amarelamento de tecidos e órgãos (Santos 2000).

A baixa incidência de icterícia talvez possa ser explicada pela grande suscetibilidade dos ovinos jovens à intoxicação pela braquiária, Isso foi demonstrado experimentalmente em ovinos da raça Santa Inês que durante o curso clínico agudo, apresentaram sinais graves da intoxicação e morreram sem exibirem icterícia (Santos Jr 2008, Castro et al. 2011).

As principais alterações observadas durante a necropsia foram semelhantes às previamente descritas em ovinos intoxicados pela gramínea (Lemos et al. 1996, Driemeier et al. 2002, Lemos \& Purisco 2002, Brum et al. 2007, Mendonça et al. 2008, Santos et al. 2008).

A emaciação e atrofia gelatinosa das reservas corporais de gordura nos animais intoxicados poderia estar relacionadas com alterações no metabolismo dos hepatócitos, associadas à baixa ingestão de alimentos (Driemeier et al. 1999). 0 aumento de volume hepático e alteração na coloração do órgão podem ser explicados principalmente devido às alterações microscópicas decorrentes da ação hepatotóxica da gramínea.

As alterações histopatológicas observadas neste estudo são semelhantes aos achados descritos anteriormente em ovinos intoxicados por braquiária (Graydon et al. 1991, Lemos et al. 1996, Driemeier et al. 1998, Tokarnia et al. 2000, Cruz et al. 2001, Torres \& Coelho 2003, Gomar et al. 2005).

A tumefação dos hepatócitos, proliferação de ductos biliares, colestase e infiltrado inflamatório mononuclear foram frequentemente observados nos ovinos intoxicados, e possivelmente, são os principais responsáveis pela hepatomegalia e alterações na coloração hepática. Santos Jr (2008) demonstrou que boa parte do processo de tumefação de hepatócitos observado no exame histopatológico de ovinos intoxicados por $B$. decumbens era decorrente de acentuada proliferação do retículo endoplasmático liso. A hiperplasia de ductos biliares é considerada uma resposta inespecífica a diversas agressões ao fígado. 0 mecanismo responsável por essa proliferação não é conhecido (Cullen 2009).

A presença de macrófagos com citoplasma espumoso no interior dos sinusoides hepáticos $(63,6 \%)$ foi um dos principais achados histopatológicos nos ovinos intoxicados naturalmente por braquiária. Essa alteração também foi observada frequentemente em ovinos experimentalmente intoxicados pela gramínea (Santos Jr. 2008). Macrófagos com citoplasma espumoso podem apresentar, algumas vezes, imagem negativa de cristais acutiformes no citoplasma. Esses cristais se formam a partir da ligação da saponina litogênica, presente nas braquiárias, ao ácido glicurônico, formando glicuronídeos que, por sua vez, se ligam a sais de cálcio formando cristais insolúveis (Cheeke 1995, Cruz et al. 2001, Driemeier et al. 2002, Santos et al. 2008). Os macrófagos espumosos também são observados em fígados de animais intoxicados por outras plantas que contêm saponinas esteroidais litogênicas, como Nathercium ossifragatum (Wisløff et al. 2002).

Das onze propriedades investigadas (S1 a S11) tinham pastos formados por $B$. decumbens. A maioria dos casos de intoxicação natural por braquiária em ovinos no Brasil ocorreram em pastos de B. decumbens (Soares et al. 2000, Silva et al. 2006, Brum et al. 2007, Mendonça et al. 2008) e $B$. decumbens consorciada com $B$. humidicola (Lemos et al. 1996). Acredita-se que o maior número de casos de intoxicação natural de ovinos por $B$. decumbens está relacionado com a maior toxicidade dessa espécie de capim, devido ao seu maior teor de saponinas esteroidais litogênicas (Riet-Correa et al. 2011).

No presente estudo, a forrageira apresentou ampla variação na altura do capim nos piquetes onde ocorreram os casos de intoxicação natural. Surtos de intoxicação natural por Brachiaria spp. em ovinos foram descritos em diversos estágios vegetativos da planta, demonstrando a alta toxicidade dessa forrageira para a espécie (Lemos et al. 1996, Brum et al. 2007).

A braquiária é tóxica para ovinos em diferentes estágios 
de crescimento da planta (brotação, crescimento e sementação), embora apresente maior toxicidade na fase de brotação (Santos Jr. 2008). Apesar de haver intoxicação natural em bovinos no final da seca, esses casos tendem a ocorrer com maior frequência após as primeiras chuvas, coincidindo com o período de rebrota da planta (Lemos \& Leal 2008). Maior toxicidade da gramínea, em casos naturais, vem sendo relatada após queimadas ou secas prolongadas, quando a forrageira se encontra em brotação (Riet-Correa \& Mendez 2007).

A mensuração dos níveis de saponina (protodioscina) realizada em cinco das 11 propriedades acompanhadas ocorreu em três delas no período da seca ( $\mathrm{S} 1=0,30 \%$, S2 $=1,06 \%$ e $S 8=0,80 \%$ ), e em duas, no período das chuvas ( $S 5=2,56 \%$ e $S 6=1,29 \%$ ). Na época chuvosa os piquetes encontravam-se em brotação e com níveis mais elevados de protodioscina que as amostras do período da seca, onde o capim se apresentava em sementação ou em fase de queda de sementes. Na propriedade (S1) onde o nível de saponina foi mais baixo, a morbidade foi de 6,6\% e nenhum animal morreu. Na propriedade (S5) onde ocorreu a intoxicação natural por Brachiaria spp. de um animal adulto, a pastagem apresentava o nível mais elevado de saponinas $(2,56 \%)$ desse estudo. Na outra propriedade (S6), com o segundo maior nível de saponina nas amostras de capim, observou-se elevada letalidade (60\%) dos animais intoxicados.

Níveis de protodioscina, variando de 0,52\% a 1,06\%, foram encontrados em pastagem madura de B. decumbens na fase final de sementação, capaz de intoxicar e provocar a morte de ovinos jovens (Castro et al. 2011). Experimentalmente, piquetes em estágio de brotação, crescimento e maduro apresentaram respectivamente 2,03\%, 1,63\% e 1,26\% de saponina na constituição da forrageira, correspondendo a maior toxicidade para ovinos nas amostras com maior quantidade do princípio tóxico (Santos Jr 2008). Essa observação foi posteriormente demonstrada em amostras de $B$. brizantha que apresentaram maior concentração de saponina nas plantas jovens $(3,61 \% \pm 1,12 \%)$ em relação ao capim maduro $(1,01 \% \pm 0,79 \%)$ (Barbosa-Ferreira et al. 2009).

No Brasil, ainda há poucos estudos de intoxicação por braquiária em ruminantes com a mensuração dos níveis de saponina nas pastagens. De qualquer forma, essas informações retratam uma amplitude muito grande nos níveis presentes nas pastagens que são suficientes para provocar intoxicação em ovinos. Esta espécie, considerada uma das mais suscetíveis à intoxicação por braquiária, pode adoecer mesmo com baixos níveis de protodioscina na forrageira.

No presente estudo foi avaliada a quantidade de esporos de Pithomyces chartarum nos pastos em que ocorreram intoxicações naturais por braquiária sendo que, em $81,8 \%$ dos surtos acompanhados, não foram encontrados esporos do fungo nas amostras. Outros casos naturais de intoxicação em ruminantes por braquiária também não demonstraram a presença de esporos do fungo nas pastagens (Lemos et al. 1996, 1998, Brum et al. 2007, Mendonça et al. 2008).

A ausência ou as baixas contagens de esporos nas pastagens observadas nesse estudo, associadas aos níveis de saponina nas pastagens e às alterações clínico-patológicas nos animais intoxicados, reforçam que o agente causal da intoxicação seja um componente da própria Brachiaria sp. Em pastagens de $B$. decumbens, onde ocorreram intoxicação e morte de ovinos, foram demonstradas a ausência ou contagens muito baixas de esporos (variação de 0 a 5000 por grama de capim fresco) do fungo $P$. chartarum para serem associadas à toxicidade (Castro et al. 2007, Santos Jr 2008).

0 presente trabalho demonstrou algumas faces de um problema que a pecuária brasileira enfrenta desde a introdução das pastagens de braquiária no País. Foi demonstrada a enorme variação do impacto que a gramínea pode ter nos rebanhos, sob a forma de animais mortos e doentes, ficando claro que ovinos jovens são mais suscetíveis à intoxicação pela gramínea.

Isto abre precedente para a necessidade premente de se compreender melhor os mecanismos envolvidos na resistência/suscetibilidade, as diferenças raciais e etárias, visando a adaptação de animais e/ou seleção de rebanhos resistentes, melhor adaptados ao pastejo da braquiária. Este estudo também reforça a importância de se avaliar melhor quais são os níveis realmente tóxicos de saponinas nas pastagens para ruminantes, o que claramente inclui um projeto de âmbito nacional. 0 estudo aprofundado, incluindo a quantificação sistemática do princípio tóxico nos surtos pelo Brasil, nas várias espécies de braquiária, em seus diferentes estágios vegetativos, em condições climáticas e regionais diversas, é uma necessidade que urge para a solução definitiva da questão.

Prejuízos ainda incalculáveis causados pela toxicidade da principal forrageira formadora das pastagens no Brasil não podem ser ignorados. Devem ser minimizados, pois, ao mesmo tempo que reduz a produtividade dos rebanhos, a gramínea, por suas qualidades, tem permitido grande expansão agropecuária para novas fronteiras.

Agradecimentos.- Ao Conselho Nacional de Pesquisa (CNPq) pelo suporte financeiro. Projeto financiado pelo Instituto de Ciência e Tecnologia para o Controle das Intoxicações por Plantas (Proc. CNPq 573534/20080) e Bolsa Produtividade (Proc. CNPq 308700/2009-0). Aos Doutores Mitsue Haraguchi e Marcos Barbosa Ferreira pela mensuração de saponinas nas amostras das pastagens.

\section{REFERÊNCIAS}

Amorim R.M., Borges A.S., Kuchembuck G., Takahira R.K. \& Alencar N.X. 2003. Bioquímica sérica e hemograma de bovinos antes e após a técnica de biópsia hepática. Ciência Rural 33:519-523.

Barbosa J.D., Oliveira C.M.C., Tokarnia C.H. \& Peixoto P.V. 2006. Fotossensibilização hepatógena em eqüinos pela ingestão de Brachiaria humidicola (Gramineae) no Estado do Pará. Pesq. Vet. Bras. 26:147-153.

Barbosa-Ferreira M., Brum K.B., Fernandes C.E.S., Martins C.F., Monteiro L.C., Rezende K.G., Riet-Correa F., Haraguchi M., Wysocki Junior H.L. \& Lemos R.A.A. 2011. Variations of saponin level x maturation in Brachiaria brizantha leaves, p.118-123. In: Riet-Correa F., Pfister J., Schild A.L. \& Wierenga T. (Eds), Poisoning by Plants, Mycotoxins and related Toxins. CAB International, London.

Brum K.B., Haraguchi M., Lemos R.A.A., Riet-Correa F. \& Fioravanti M.C.S. 2007. Crystal-associated cholangiopathy in sheep grazing Brachiaria decumbens containing the saponin protodioscin. Pesq. Vet. Bras. 27:39-42.

Castro M.B., Moscardini A.R.C., Reckziegel G.C., Novaes E.P.F., Mustafa V.S., Paludo G.R., Borges J.R.J. \& Riet-Correa F. 2007. Susceptibilidade de ovinos a intoxicação por Brachiaria decumbens. Anais V Congreso Latino- 
americano de Especialistas en Pequeños Rumiantes y Camélidos Sudamericanos, Buenos Aires, p.57-59.

Castro M.B., Santos Jr. H.L., Mustafa V.S., Gracindo C.V., Moscardini A.C.R., Louvandini H., Paludo G.R., Borges J.R.J., Haraguchi M., Ferreira M.B. \& Riet-Correa, F. 2011. Brachiaria spp. poisoning in sheep in Brazil. Experimental and epidemiological findings, p.110-117. In: Riet-Correa F., Pfister J., Schild A.L. \& Wierenga T. (Eds), Poisoning by Plants, Mycotoxins and related Toxins. CAB International, London.

Cheeke P.R. 1995. Endogenous toxins and mycotoxins in forage grasses and their effects on livestock. J. Anim. Sci. 3:909-918.

Cruz C., Driemeier D., Pires V.S., Colodel E.M., Taketa A.T.C. \& Schenkel E. 2000. Isolation of steroidal sapogenins implicated in experimentally induced cholangiopathy of sheep grazing Brachiaria decumbens in Brazil. Vet. Human Toxicol. 42:142-145.

Cruz C., Driemeier D., Pires V.S. \& Schenkel E.P. 2001. Experimentally induced cholangiohepatopathy by dosing sheep with fractionated extracts from Brachiaria decumbens. J. Vet. Diagn. Invest. 13(2):170-172.

Cullen J.F. 2009. Fígado, sistema biliar e pâncreas, p.393-461. In: McGavin M.D. \& Zachary J.F. (Eds), Bases da Patologia em Veterinária. 4ํㅡㄹ ed. Elsevier, Rio de Janeiro.

Di Menna M.E. \& Bailey J.R. 1973. Pithomyces chartarum spore counts in pasture. N.Z. J. Agric.Res. 16:343-351.

Driemeier D., Barros S.S., Peixoto P.V., Tokarnia C.H., Döbereiner J. \& Brito M.F. 1998. Estudo histológico, histoquímico e ultra-estrutural de fígados e linfonodos de bovinos com presença de macrófagos espumosos ("foam cells"). Pesq. Vet. Bras. 18:29-34.

Driemeier D., Döbereiner J., Peixoto P.V. \& Brito M.F. 1999. Relação entre macrófagos espumosos ("foam cells") no fígado de bovinos e ingestão de Brachiaria spp. no Brasil. Pesq. Vet. Bras. 19:79-83.

Driemeier D., Colodel E.M., Seitz A.L., Barros S.S. \& Cruz C.E.F. 2002. Study of experimentally induced lesions in sheep by grazing Brachiaria decumbens. Toxicon 40:1027-1031.

Gjulemetowa R., Tomowa M., Simowa M., Pangarowa T. \& Peewa S. 1982. Über die bestimmung von furostanolsaponinen im präparat tribestan®. Pharmazie 37:296.

Gomar M.S., Driemeier D., Colodel E.M. \& Gimeno E.J. 2005. Lectin histochemistry of foam cells in tissues of cattle grazing Brachiaria spp. J. Vet. Med. Physiol. Pathol. Clin. Med. 52:18-21.

Graydon R.I., Hamid H. \& Zahari P. 1991. Photosensitization and crystal associated cholangiohepatopathy in sheep grazing Brachiaria decumbens. Aust. Vet. J. 68:234-236.

Khairi H.M., Elsheikh H.A. \& Abdullah A.S. 2000. The effect of signal grass (Brachiaria decumbens) on drug-metabolizing enzymes in sheep and comparison with normal cells. Vet. Human Toxicol. 42:193-195.

Lemos R.A.A., Ferreira L.C.L., Silva S.M., Nakazato L. \& Salvador S.C. 1996. Fotossensibilização e colangiopatia associada a cristais em ovinos em pastagem com Brachiaria decumbens. Ciência Rural 26:109-113.

Lemos R.A.A., Salvador S.C. \& Nakazato L. 1997. Photosensitization and crystal associated cholangiohepatopathy in cattle grazing Brachiaria decumbens in Brazil. Vet. Human Toxicol. 39:376-377.

Lemos R.A.A., Oliveira V.A., Herrero Jr G.O., Silveira A.C. \& Porfírio L.C. 1998. Fotossensibilização e colangiopatia associada a cristais em caprinos mantidos sob pastagens de Brachiaria decumbens no Mato Grosso do Sul. Ciência Rural 28:507-510.

Lemos R.A.A. \& Purisco E. 2002. Plantas que causam fotossensibilização hepatógena, p.292 In: Lemos R.A.A., Barros N. \& Brum K.B. (Eds), Enfermidades de Interesse Econômico em Bovinos de Corte: perguntas e respostas. Ed. UFMS, Campo Grande, MS.

Lemos R.A.A. \& Leal C.R.B. 2008. Doenças de impacto econômico em bovinos de corte: perguntas e respostas. Ed. UFMS, Campo Grande, MS. 450p.

Lemos R.A.A., Nogueira A.P.A., Souza R.I.C., Santos B.S., Carvalho N.M., Aniz A.C.M. \& Freitas P.C. 2011. Brachiaria spp. poisoning in ruminants in Mato Grosso do Sul, Brazil, p.129-132. In: Riet-Correa F., Pfister J., Schild
A.L. \& Wierenga T. (Eds), Poisoning by Plants, Mycotoxins and related Toxins. CAB International, London.

Macêdo J.T.S.A., Riet-Correa F., Dantas A.F.D. \& Simões S.V.D. 2008. Doenças da pele em caprinos e ovinos no semi-árido brasileiro. Pesq. Vet. Bras. 28(12):633-642.

Mendonça F.S., Camargo L.M., Freitas S.H., Dória R.G.S., Baratella-Evêncio L. \& Evêncio Neto J. 2008. Aspectos clínicos e patológicos de um surto de fotossensibilização hepatógena em ovinos pela ingestão de Brachiaria decumbens (Gramineae) no município de Cuiabá, Mato Grosso. Ciênc. Anim. Bras. 9(4):1034-1041.

Purchio A., Correa B., Galhardo M. \& Pelicci P. 1988. Ocorrência de surto de eczema facial em ovinos, na região de São Manuel, estado de São Paulo. Revta Fac. Med. Vet. Zoot. USP 25(1):135-137.

Riet-Correa B., Castro M.B., Lemos R.A.A., Riet-Correa G., Mustafa V. \& Riet-Correa F. 2011. Brachiaria spp. poisoning of ruminants in Brazil. Pesq. Vet. Bras. 31(3):183-192.

Riet-Correa F. \& Méndez M.D.C. 2007. Intoxicações por plantas tóxicas e micotoxinas, p.99-221. In: Riet-Correa F., Schild A.L., Lemos R.A.A. \& Borges J.R.J. (Eds), Doenças de Ruminantes e Eqüídeos. Vol.2. 3aㅡ ed. Pallotti Editora, Santa Maria.

Riet-Correa F., Medeiros R.M.T., Pfister J., Schild A.L. \& Dantas A.F.M. 2009. Poisonings by Plants, Mycotoxins and related Substances in Brazilian Livestock. Pallotti Editora, Santa Maria, p.53-92.

Rissi D.R., Rech R.R., Pierezan F., Gabriel A.L., Trost M.E., Brum J.S., Kommers G.D. \& Barros C.S.L. 2007. Intoxicações por plantas e micotoxinas associadas a plantas em bovinos no Rio Grande do Sul: 461 casos. Pesq. Vet. Bras. 27(7):261-268.

Salam Abdullah A., Nordin M.M. \& Rajion M.A. 1988. Signal grass (Brachiaria decumbens) toxicity in sheep: changes in motility and $\mathrm{pH}$ of reticulo-rumen. Vet. Human Toxicol. 30:256-258.

Salam Abdullah A., Lajis N.H., Bremner J.B., Davies N.W., Mustapha W. \& Rajion M.A. 1992. Hepatotoxic constituents in the rumen of Brachiaria decumbens intoxicated sheep. Vet. Human Toxicol. 34:154-155.

Santos R.I. 2000. Metabolismo básico e origem dos metabólitos secundários, p.323-354. In: Simões C.M.O., Schenkel E.P., Gosmann G., Mello J.C.P., Mentz L.A. \& Petrovick P.R. (Eds), Farmacognosia da Planta ao Medicamento. Editoras da UFRGS, Porto Alegre, e UFSC, Florianópolis.

Santos J.C.A., Riet-Correa F., Simões S.V. \& Barros C.S.L. 2008. Patogênese, sinais clínicos e patologia das doenças causadas por plantas hepatotóxicas em ruminantes e equinos no Brasil. Pesq.Vet. Bras. 28(1):1-14.

Santos Jr H.L. 2008. Estudo da toxicidade de diferentes estágios de crescimento de Brachiaria decumbens em ovinos. Dissertação de Mestrado em Saúde Animal, Faculdade de Agronomia e Medicina Veterinária, Universidade de Brasília, Brasília, DF. 70p.

Schild A.L. 2007. Doenças tóxicas: fotossensibilização hepatógena, p.39-42. In: Riet-Correa F., Schild A.L., Lemos R.A.A. \& Borges J.R.J. (Eds), Doenças de Ruminantes e Eqüídeos. Vol.2. 3ํㅗ ed. Palloti Editora, Santa Maria.

Silva D.M., Riet-Correa F., Medeiros R.M.T. \& Oliveira O.F. 2006. Plantas tóxicas para ruminantes e eqüídeos no Seridó Ocidental e Oriental do Rio Grande do Norte. Pesq. Vet. Bras. 26(4):223-236.

Soares P.C., Mota R.A., Teixeira M.N. \& Santos V.M. 2000. Aspectos epidemiológicos e clínicos da intoxicação por Pithomyces chartarum em ovinos da raça Santa Inês, no município de Gravatá-PE. Revta. Bras. Ciênc. Vet. 7(2):78-82.

Stegelmeier B.L. 2002. Equine photosensitization. Clin. Tech. Eq. Pract. 2:81-88.

Tokarnia C.H., Döbereiner J. \& Peixoto P.V. 2000. Plantas Tóxicas do Brasil. Editora Helianthus, Rio de Janeiro. 310p.

Torres M.B.A.M. \& Coelho K.L.R. 2003. Foamy macrophages in the liver of cattle fed Brachiaria brizantha hay. Vet. Human Toxicol. 45(3):163-164.

Wisløf H., Wilkins A.L., Scheie E. \& Flåøyen A. 2002. Accumulation of sapogenin conjugates and histological changes in the liver and kidneys of lambs suffering from alveld, a hepatogenous photosensitization disease of sheep grazing Narthecium ossifragum. Vet. Res. Commun. 26:381-396. 